\title{
Polar-Orientated Mg-O Layers on Ag(111): a STM Study*
}

\author{
M. Mantilla, N. Jedrecy, ${ }^{\dagger}$ R. Lazzari, and J. Jupille \\ Institut des NanoSciences de Paris, Universite Pierre et Marie Curie-Paris \\ 6 and CNRS-UMR 7588, 4 Place Jussieu 75252 Paris Cedex 05, France \\ (Received 31 May 2008; Accepted 1 December 2008; Published 4 April 2009)
}

\begin{abstract}
We report on a scanning tunneling microscopy (STM) study of Mg-O surfaces obtained from ultra-thin $\mathrm{Mg} / \mathrm{Ag}(111)$ layers exposed to different doses of oxygen at room temperature. Large scale images of any of the $\mathrm{Mg}-\mathrm{O}$ surfaces show faintly corrugated alignments of $2-2.5 \mathrm{~nm}$ wide elementary dots. For adequate $\mathrm{O}_{2}$ pressure with respect to the nominal $\mathrm{Mg}$ coverage, the dots are aligned along the $\langle 112\rangle$ directions of silver. A hexagonal array of dots with a $4.5 \mathrm{~nm}$ periodicity may even be obtained, which we attribute to an epitaxial $\mathrm{Mg}-\mathrm{O}$ (111) layer with in-plane spacing equal to 3.0 or $3.2 \mathrm{~nm}$.
\end{abstract}

[DOI: $10.1380 /$ ejssnt.2009.476]

Keywords: Scanning tunneling microscopy; $\mathrm{MgO}$; $\mathrm{Ag}(111)$; Surface structure, morphology, roughness, and topography; Nanostructures; Magnesium oxides

\section{INTRODUCTION}

Ultra-thin oxide films attract increased interest for the development of new systems in spintronics [1-3] or in catalysis [4, 5]. Unreconstructed, polar-orientated oxide thin films might be promising candidates in both fields. While bulk-truncated polar surfaces are intrinsically unstable due to the divergence of the electrostatic potential [6], leading to surface depolarization mechanisms, the situation may be by far different in the case of a finite system [7]. In particular, reconstruction-free surfaces with high reactivity may be anticipated as well as metal-insulator transition as a function of thickness. $\mathrm{MgO} / \mathrm{Ag}(111)$ is an attractive model system in this respect. $\mathrm{MgO}$ is a simple highly ionic (sp orbitals) oxide with the rock-salt (RS) structure and a wide band gap (7.8 $\mathrm{eV})$. It is expected that the $\mathrm{MgO}(111)$ orientation, which results in equidistant charged layers, should be driven by the $\operatorname{Ag}(111)$ substrate (3.1\% of lattice mismatch), with an abrupt interface. The most recent $a b$ initio calculations on $\mathrm{MgO}(111)$ films [8] predict several structural configurations as possible in the low thickness regime: uncompensated RS (111), compensated boron-nitride (BN) (0001) and uncompensated zinc-blende (ZB) (111). Unreconstructed $\mathrm{MgO}(111)$ thin films have been reported to be grown on $\mathrm{Ag}(111)$ [9] and on $\mathrm{Mo}(110)$ [10] substrates, by means of alternate deposition of $\mathrm{Mg}$ and $\mathrm{O}_{2}$. However, the structural information relied exclusively on electron diffraction patterns. We report here on a scanning tunnelling microscopy (STM) study of the oxidation process at room temperature of ultra-thin $\mathrm{Mg}$ layers preliminary deposited in ultra high vacuum (UHV) on $\mathrm{Ag}(111)$, and on the different types of $\mathrm{MgO}$ nanostructures that are obtained in this way.

\footnotetext{
* This paper was presented at the 14th International Conference on Solid Films and Surfaces (ICSFS-14), Trinity College Dublin, Ireland, 29 June - 4 July, 2008.

$\dagger$ Corresponding author: jedrecy@insp.jussieu.fr
}

\section{EXPERIMENTAL}

The $\operatorname{Ag}(111)$ substrate was cleaned by repeated cycles of $\mathrm{Ar}^{+}$sputtering and annealing until STM images showed atomically stepped terraces, several hundreds of nanometers wide, free from contaminants. Mg was evaporated at room temperature using either an electron beam cell or an effusion cell, calibrated by means of a quartz microbalance. The oxidation was followed in situ by STM exposing the $\mathrm{Mg} / \mathrm{Ag}(111)$ films several minutes to an $\mathrm{O}_{2}$ atmosphere of $2 \times 10^{-8} \mathrm{mbar}$ or of $5 \times 10^{-6} \mathrm{mbar}$. We used electrochemically etched $\mathrm{W}$ tips, tentatively Ag-coated by applying bias pulses prior to $\mathrm{Mg}$ deposit.

\section{RESULTS AND DISCUSSIONS}

Figure 1(a) shows a $100 \times 100 \mathrm{~nm}^{2}$ image of a sample with a nominal $\mathrm{Mg}$ coverage of 1 monolayer (ML). Flat, irregularly shaped islands are observed, whose apparent height is close to the $c / 2$ bulk lattice parameter of $\mathrm{Mg}$ (260 pm), suggesting the supporting terrace is here of $\mathrm{Mg}$ nature. Various sample bias voltages can be used for the $\mathrm{Mg} / \mathrm{Ag}(111)$ image recording. In order to be ensured of tunnelling conditions throughout the following $\mathrm{O}_{2}$ exposure, sample voltage was thereafter fixed to $-3 \mathrm{~V}$ (Fig. 1(b)), a value which has been proven sufficient to image insulating $\mathrm{MgO}(001)$ films in the $\mathrm{ML}$ range [11-13], while allowing image recording without insurmountable tip/surface damages. The image 1 (c) displays the surface 10 min after a first $\mathrm{O}_{2}$ dosing ( 3 min to $2 \times 10^{-8}$ mbar). A uniform population of dots whose lateral size is about $2.5 \mathrm{~nm}$ is revealed at the surface of the main island as well as on the supporting terrace. The overall roughness of the surface has significantly increased with respect to 1(b), height variations up to $\sim 250 \mathrm{pm}$ being measured when scanning on top of the main island. Figure $1(\mathrm{~d})$ shows the surface $10 \mathrm{~min}$ after a second $\mathrm{O}_{2}$ dosing $(6 \mathrm{~min}$ to $2 \times 10^{-8} \mathrm{mbar}$ ). The density of dots has raised and dot alignments emerge along badly defined directions. The surface was then exposed a third time to oxygen (15 min, $2 \times 10^{-8}$ mbar $)$. At this stage of oxidation, the island shape together with the dot alignment undergoes some al- 

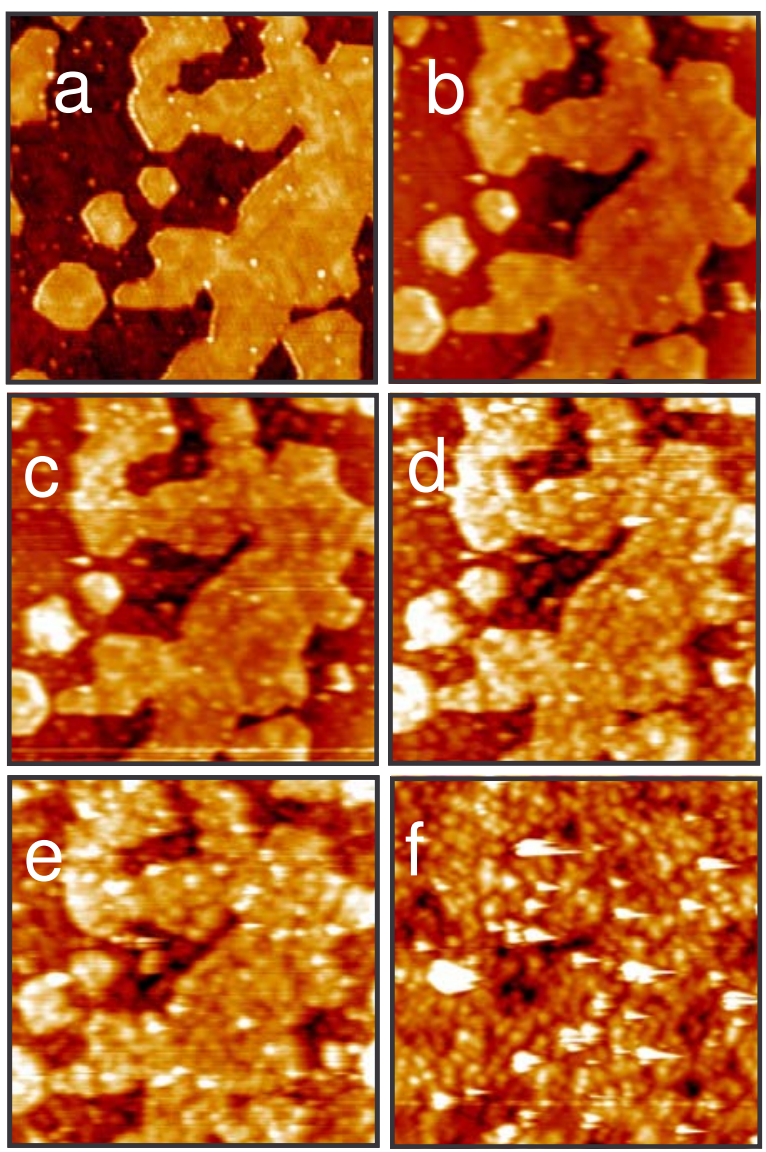

FIG. 1: (a),(b): $100 \times 100 \mathrm{~nm}^{2}$ STM images of a $\sim 1.5 \mathrm{ML}$ $\mathrm{Mg} / \mathrm{Ag}(111)$ surface $[-0.6 \mathrm{~V}, 50 \mathrm{pA}$ for $(\mathrm{a}),-3 \mathrm{~V}, 20 \mathrm{pA}$ for (b)]. (c)-(f): Images $(-3 \mathrm{~V}, 20 \mathrm{pA})$ of the same film after successive increasing oxygen exposures (from $3 \mathrm{~min}$ at $2 \times 10^{-8}$ mbar to $8 \mathrm{~min}$ at $\left.1 \times 10^{-7} \mathrm{mbar}\right)$.

terations (Fig. 1(e)). In particular, smaller but straighter dotted segments are constituted. After a fourth $\mathrm{O}_{2}$ dosing ( 8 min to $1 \times 10^{-7} \mathrm{mbar}$ ), the whole surface has reacted (Fig. 1(f)), the shape of the starting $\mathrm{Mg}$ islands being no more recognizable. Close inspection of the image (top left for instance) reveals hexagonal-like arrangements of the dots, with one direction rotated by $\sim 30^{\circ}$ with respect to the horizontal axis.

To ensure a rapid and full oxidation of the deposited $\mathrm{Mg}$ layers, the other experiments were done using an $\mathrm{O}_{2}$ pressure of $5 \times 10^{-6}$ mbar (2 min exposure time). Several $\mathrm{Mg} / \mathrm{Ag}$ samples were investigated. Figure 2(a) shows the surface of a nominal $3 \mathrm{ML} \mathrm{Mg/Ag} \mathrm{film.} \mathrm{Figures} \mathrm{2(b)} \mathrm{and}$ (c) display the surface immediately and 5 min after $\mathrm{O}_{2}$ exposure. Here again, the $\mathrm{Mg}$ layer burst into dots upon $\mathrm{O}_{2}$ exposure, the dots organizing themselves in the form of lines with preferential directions. Along these lines, the average separation between dots is $\sim 4.5 \mathrm{~nm}$. One dotted line direction is turned by about $-30^{\circ}$ with respect to the horizontal axis, the latter having been preliminary identified as a close-packed axis $(\langle 110\rangle)$ of the silver substrate. Angles of 60 or $120^{\circ}$ between the lines are clearly recognized in some locations. In Fig. 2(d), we compare the height histogram of a chosen region of image $2(\mathrm{c})$ to that before oxidation. The height distribution of the oxidized
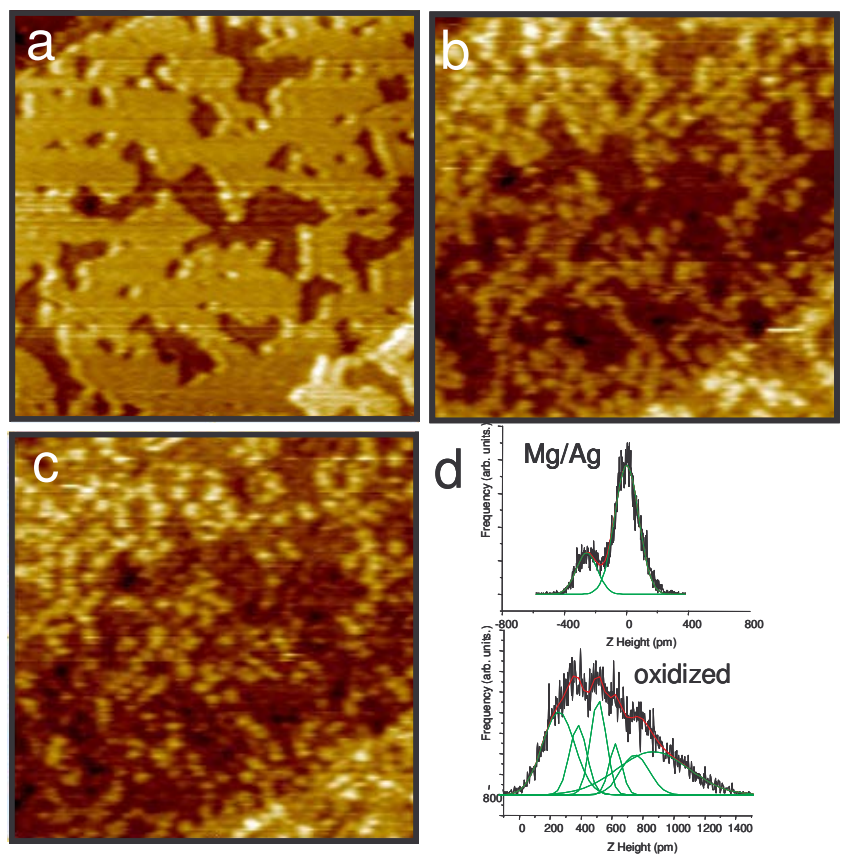

FIG. 2: (a)-(c): $100 \times 100 \mathrm{~nm}^{2}$ STM image $(0.3 \mathrm{~V}, 50 \mathrm{pA})$ of $\mathrm{a} \sim 3 \mathrm{ML} \mathrm{Mg} / \mathrm{Ag}$ film, before and after oxygen exposure (d): Height distributions from images (a) and (c).

film has increased with respect to that of the $\mathrm{Mg}$ film, several components (instead of two) distant by about $120 \mathrm{pm}$ (instead of $260 \mathrm{pm}$ ) being extracted from the new profile. The smallest distance between (111) layers in bulk $\mathrm{MgO}$ is $121.5 \mathrm{pm}$, in accordance with the experimental apparent heights. The identification of at least 4 layers in the oxidized film suggests oxygen atoms incorporate below as well as above any exposed $\mathrm{Mg}$ layer.

A well ordered array of dots could be obtained oxidizing a uniform, nominally $1 \mathrm{ML}, \mathrm{Mg} / \mathrm{Ag}(111)$ film (see Figs. 3(a)-(b)). The Fourier Transform (FT) of one of the oxidized terrace is shown in $3(\mathrm{c})$. It takes the form of a hexagonal pattern turned by $30^{\circ}$ with respect to the one obtained from the Ag template (LEED and STM measurements not shown here). The periodicity between dots is found equal to $4.5 \pm 0.2 \mathrm{~nm}$, the dot size is $\sim 2.5 \mathrm{~nm}$. The corrugation along closest-packed dots is $\sim 40 \mathrm{pm}$. In addition, the STM image reveals a super-periodicity of $\sim 3 \times 4.5 \mathrm{~nm}$ in the dotted arrangement, through triangular topographical contours. Apparent heights of $\sim 120$ pm are measured along a given terrace (see the height histogram in 3(d) as well as the line profile in $3(\mathrm{e}))$, confirming the previous estimation of the interlayer spacing in our $\mathrm{Mg}-\mathrm{O} / \mathrm{Ag}(111)$ ultra-thin films. For comparison, the interlayer spacing in $\mathrm{MgO}(001)$ is $210.5 \mathrm{pm}$.

All observations are consistent with polar-orientated Mg-O layers akin to RS $\mathrm{MgO}(111)$ layers. First, the apparent heights obtained from scans at the surface of an oxidized terrace are half the value that should be measured (at $-4 \mathrm{~V}$ ) in the case of $\mathrm{MgO}(001)$ layers [11]. Second, the local hexagonal organization of the dots, observed for $\mathrm{Mg}$ films exposed to high doses of $\mathrm{O}_{2}$, points towards a hexagonal in-plane atomic structure, at variance with the three (rotated by $120^{\circ}$ from each other) (001) domains of quadratic symmetry that could be con- 

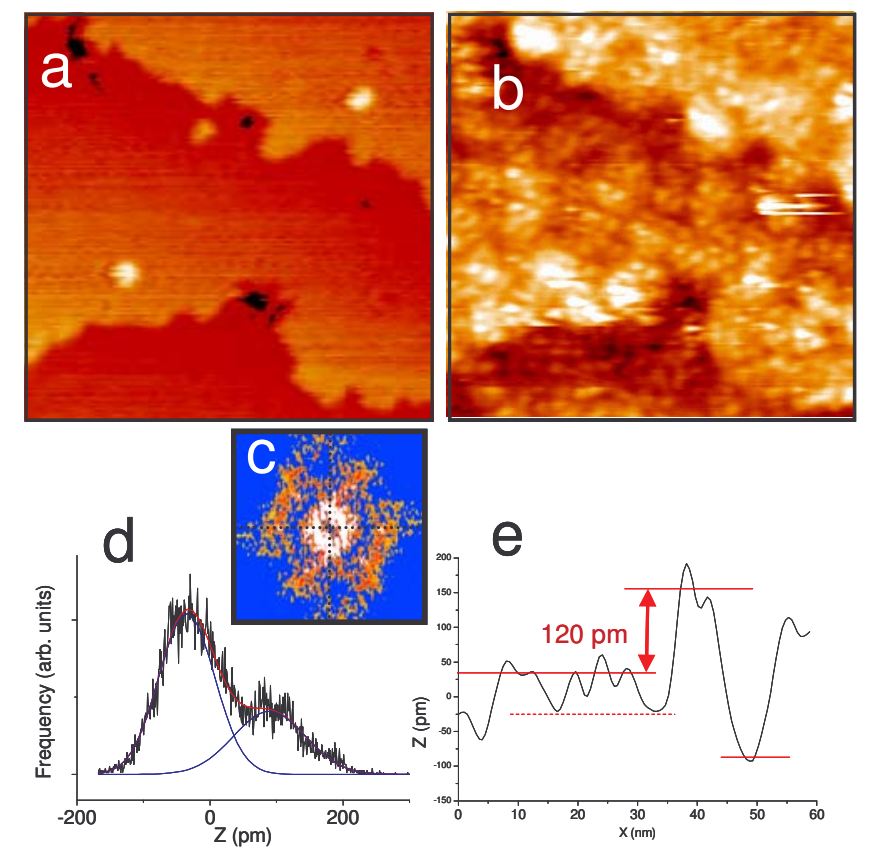

FIG. 3: (a)-(b): $100 \times 100 \mathrm{~nm}^{2}$ STM images of a $\sim 1 \mathrm{ML} \mathrm{Mg} / \mathrm{Ag}$ film before and after oxidation, using an $\mathrm{O}_{2}$ pressure of $5 \times 10^{-6}$ mbar [-4 V, $20 \mathrm{pA}$ for (b)]. (c): The Fourier Transform of image (b). (d),(e): Height histogram and height line profile from (b), respectively.

ceived on $\operatorname{Ag}(111)$. Third, the morphological and topographical features of the $\mathrm{Mg}-\mathrm{O} / \mathrm{Ag}(111)$ STM images were obtained using various bias voltages (from -0.7 to -4 $\mathrm{V})$, suggesting a metallic nature of the oxidized films, in accordance with the EELS measurements and the density functional calculations of Ref. [14]. This electronic behaviour is quite distinct from the insulating one reported for $\mathrm{MgO}(001)$ layers $[11,15]$. Last but not least, the recurrent hexagonal $4.5 \mathrm{~nm}$ periodicity may be accounted for, by considering RS $\mathrm{MgO}(111)$ layers epitaxial with respect to $\mathrm{Ag}(111)$, with azimuthal orientation: $\langle 110\rangle \mathrm{MgO} / /\langle 112\rangle \mathrm{Ag}[16]$. Indeed, the closest-packed dot directions are along the $\langle 112\rangle \mathrm{Ag}$ axes, and a noticeable point is that $4.5 \mathrm{~nm}$ correspond to a site-to-site distance in silver (nine $(\sqrt{3} \times \sqrt{3}) \mathrm{R} 30^{\circ}$ unit cells of $\mathrm{Ag}$, exactly). The lattice parameter of the surface $(1 \times 1)$ unit cell of bulk $\mathrm{MgO}(111)$ being $0.298 \mathrm{~nm}$, fifteen such $(1 \times 1) \mathrm{MgO}$ cells, rotated by $30^{\circ}$ with respect to the $(1 \times 1) \mathrm{Ag}$ cell, would match at $-0.67 \%$ with every $4.5 \mathrm{~nm} \mathrm{Ag}$ site. A perfect $4.5 \mathrm{~nm}$ coincidence between $\mathrm{MgO}$ and $\mathrm{Ag}$ lattices is obtained assuming a $\mathrm{MgO}(1 \times 1)$ lattice parameter either equal to $0.3 \mathrm{~nm}$ or $0.321 \mathrm{~nm}$. In the first case (lattice parameter dilated by $0.67 \%$ with respect to bulk), $15 \mathrm{MgO}$ cells would be involved, while in the second case (lattice parameter dilated by $7.7 \%$ ), 14 cells would intervene. The $0.321 \mathrm{~nm}$ lattice parameter value is close to that reported on the same system by Kiguchi et al. (0.325 nm for a 2 ML film) [9], as well as to that calculated in the case of an unsupported BN MgO layer [17]. On contrary, experiments on submonolayer films are in favor of the surface $(1 \times 1)$ lattice parameter value equal to $0.3 \mathrm{~nm}$ [16]. One may emphasize here that the $\mathrm{MgO}(111) / \mathrm{Ag}(111)$ epitaxy with $\langle 112\rangle \mathrm{MgO} / /\langle 112\rangle \mathrm{Ag}$, associated with a bulk lattice mismatch of $3.1 \%$, could not explain the observed $4.5 \mathrm{~nm}$ hexagonal periodicity. The $\mathrm{MgO}(001) / \mathrm{Ag}(111)$ epitaxy may be excluded as well. Besides, it is beyond the present experiment to discriminate confidently between the bulkderived $\mathrm{Mg}^{2+}, \mathrm{O}^{2-}$ layer (111) stacking and slightly different stackings such as those encountered in ZB (111) or BN (0001), which were considered as metastable [8]. Also, further experiments (in particular, use of chemically sensitive techniques) are needed to investigate the exact stoichiometry of the oxidized films and the nature of the bonding at the $\mathrm{MgO}-\mathrm{Ag}$ interface, together with the eventual incorporation of $\mathrm{Ag}$ atoms in the $\mathrm{MgO}$ film.

\section{SUMMARY}

The alternate deposit of $\mathrm{Mg}$ and $\mathrm{O}_{2}$ on $\mathrm{Ag}(111)$ surface leads to long-range organized $\mathrm{Mg}-\mathrm{O}$ (111) surfaces that involve elementary dots of $2-2.5 \mathrm{~nm}$ width. Oxidation of $\sim 1 \mathrm{ML} \mathrm{Mg}$ films results, for $\mathrm{O} / \mathrm{Mg}$ ratio $>$ or $=1$, into a hexagonal array of these dots, rotated by $30^{\circ}$ with respect to the $\mathrm{Ag}$ lattice and in coincidence with it $(4.5 \mathrm{~nm}$ periodicity). The one-dimensional dot alignments observed with thicker $\mathrm{Mg}$ films or with non-completely oxidized films suggest complex stabilization mechanisms.

\section{Acknowledgments}

We would like to thank Stephane Chenot for his invaluable technical assistance and Nihed Chaabane who participated to the first STM studies. This work was partly funded by the ANR program.
[1] S. A. Chambers, Surf. Sci. Rep. 61, 345 (2006).

[2] H. J. Kim, J. E. Lee, I. G. Baek, Y. K. Ha, J. S. Bae, S. C. Oh, S. O. Park, U. I. Chung, N. I. Lee, H. K. Kang, and J. T. Moon, IEEE Trans. Magn. 40, 2616 (2004).

[3] J. Shirakashi and Y. Takemura, IEEE Trans. Magn. 40, 2640 (2004).

[4] H. J. Freund, Surf. Sci. 601, 1438 (2007).

[5] Q. Fu and T. Wagner, Surf. Sci. Rep. 62, 431 (2007).

[6] P. W. Tasker, J. Phys. C 12, 4977 (1979).

[7] J. Goniakowski, F. Finocchi, and C. Noguera, Rep. Progr. Phys. 71, 016501 (2008).
[8] J. Goniakowski, C. Noguera, and L. Giordano, Phys. Rev. Lett. 98, 205701 (2007).

[9] M. Kiguchi, S. Entani, K. Saiki, T. Goto, and A. Koma, Phys. Rev. B 68, 115402 (2003).

[10] M. Xue and Q. Guo, J. Chem. Phys. 127, 054705 (2007).

[11] S. Valeri, S. Altieri, U. del Pennino, A. di Bona, P. Luches, and A. Rota, Phys. Rev. B 65, 245410 (2002).

[12] A. M. Ferrari, S. Casassa, C. Pisani, S. Altieri, A. Rota, and S. Valeri, Surf. Sci. 588, 160 (2005).

[13] M. C. Gallagher, M. S. Fyfield, J. P. Cowin, and S. A. Joyce, Surf. Sci. 339, L909 (1995). 
[14] R. Arita, Y. Tanida, S. Entani, M. Kiguchi, K. Saiki, and H. Aoki, Phys. Rev. B 69, 235423 (2004).

[15] S. Schintke, S. Messerli, M. Pivetta, F. Patthey, L. Libioulle, M. Stengel, A. De Vita, and W.-D. Schneider, Phys. Rev. Lett. 87, 276801 (2001).
[16] M. Mantilla, N. Jedrecy, R. Lazzari, and J. Jupille, Surf. Sci. 602, 3089 (2008).

[17] J. Goniakowski, C. Noguera, and L. Giordano, Phys. Rev. Lett. 93, 215702 (2004). 